\title{
요양시설 노인의 수면의 질이 인지기능 및 우울감, 일상생활활동과의 관련성 연구
}

\author{
강은영 ${ }^{1}$, 정상미 ${ }^{2}$, 정복희 ${ }^{*}$ \\ ${ }^{1}$ 호원대학교 언어치료학과, ${ }^{2}$ 상지영서대학 작업치료학과, ${ }^{*}{ }^{3}$ 호원대학교 작업치료학과
}

\author{
The Relationship Between the Quality of Sleep and the Cognitive Function, Depression, \\ and Activities of Daily Living in the Institutionalized Elderly \\ Eun-Yeong Kang ${ }^{1}$, Sang-Mee Chong ${ }^{2}$, Bok-Hee Chong ${ }^{* 3}$ \\ ${ }^{1}$ Dept. of Speech \& language therapy, Howon University \\ ${ }^{2}$ Dept. of Occupational Therapy, Sangji Yonugseo University \\ ${ }^{*}$ Dept. of Occupational Therapy, Howon University
}

\begin{abstract}
Purpose. The purpose of this study was to determine the relationship between sleep quality and cognitive function, depression, and institutionalized elderly activity. The goal is to improve the quality of life through early intervention in the sleeping problems of the elderly hospitalized in the nursing home. Method Twenty-three patients who were diagnosed with CDR (clinical dementia grade) $0.5 \sim 2$ stages by a psychiatrist from September 3 to 30, 2017 were measured for sleep status, depression, cognitive function and activities of daily living at the same time once a day. The collected data were analyzed using SPSS (v.21, IBM, USA) program. Results The correlation between sleep status and cognitive function, depression, and activities of daily living was not statistically significant, and there was a moderate correlation between cognitive function and depression. Conclusion The results of this study suggest that the development and application of a program that activates the cognitive function that is institutionalized with a positive correlation between cognitive function and depression will be effective in decreasing depression in the elderly patients hospitalized in the nursing home.
\end{abstract}

Key Words Activities of Daily Living, cognitive function, depression, quality of sleep, Elderly,

Corresponding author Bok-Hee Chong(idnabi@empas.com)

This paper was supported by the research grant of the Howon University in 2018

Received date

Revised date

Accepted date
28 September 2018

04 October 2018

08 October 2018

\section{I. 서 론}

인간은 살아오면서 지구의 자전기능으로 해가 뜸과 동시에 하 루가 시작되고 해가 지면 잠자리에 드는 일상을 수 천년 동안 반복해 왔다. 그러나 문명과 환경, 생활방식의 변화로 현대인은 충분한 수면을 취하기 어려워졌으며 그로 인해 비만, 당뇨병, 심장병, 치매, 학습장애와 같은 다양한 합병증에 노출 되었다. ${ }^{1)}$

전 세계적으로 고령화와 함께 노인인구가 빠르게 증가되고 있는 시점에 노년기 노인은 정신적, 신체적, 사회적 측면에서 노화와 함께 수면패턴의 변화를 겪게 되는데 다수 노인은 초 저녁에 잠자리에 들고 아침 일찍 일어나는 경향이 있으며 자 는 동안 작은 소리에도 깨는 등 잠을 들지 못한다. 노인 수면
을 위한 평균시간은 점차 감소하며 잠들기가 쉽지 않다는 호 소와 함께 한국의 경우 65세 84세 노인을 대상으로 연구한 결과 $57.7 \%$ 에서 잠드는데 어려움을 호소하였다. ${ }^{2)}$

뇌 과학이 발전하면서 많은 연구가 이루어지고 있는데 잠 을 자는 이유와 기능에 대해서는 몇 가지 이유와 가설들이 설 명되고 있다. 첫째로 피로 회복 설로 잠을 자지 않거나 적게 자면 피로하고 잠을 잘 자면 피로가 풀린다는 사실로 기존에 는 뇌를 쉬게 하기 위한 생리현상이라는 통설이 대세였으나 뇌 없는 해파리도 잠을 잔다는 사실이 밝혀져 뇌만 잠을 필요 로 하는 것이 아니라 개별 뉴런들도 잠을 필요로 한다는 보고 도 있었다. ${ }^{3)}$ 수면은 사람이 일상생활을 활기차고 능률적으로 살아가기 위해서는 최적의 수면시간이 필요하며 적정 수면시 간은 평균적으로 8 시간 자는 경우가 가장 많고 많이 자는 사

http:dx.doi.org/10.17817/2018.10.04.111325 
람은 12 시간, 적은 사람은 4 시간의 요구 수면량을 나타내는데 적정 수면량은 사람마다 다를 수 있으나, 적정 수면량 이하의 수면은 건강을 해칠 수 있다.

많은 노인에서 일관성 있게 나타나는 수면 시작 후 깨우기 까지의 시간(waking after sleep onset; WASO)의 증상은 수면요구의 감소와 델타수면의 감소, 청각 역치의 감소 등의 원인으로 설명되고 있으며, ${ }^{4)}$ 나이가 들면 램 잠복기가 짦아지 면서 수면 3 4단계의 서파수면(sleep wave sleep)의 감소를 보이는데 서파수면은 소아기의 왕성하게 나타나는 수면으로 서파수면 중에 있는 아동의 경우 깨우는 것이 어려울 정도로 깊은 잠에 빠져 들게 되는데 서파수면 후 램수면이 시작되면 뇌가 깨어있어 꿈을 꾸게 되고 근육에 머물렀던 혈액이 뇌로 들어가 생각을 원활히 할 수 있게 되면 이 기간에 전체 혈액 의 $1 / 4$ 가량이 뇌에 모여 새로운 기억을 단기간 저장할 수 있 는 중요한 기능을 담당하게 되는데, ${ }^{5}$ 60세가 되면 이 서파수 면이 감소하게 되어 노인의 경우 일찍 자고 일찍 일어나거나, 수면 중 자주 깨거나, 깊은 잠을 취하지 못하는 생활이 반복 되면 기억과 학습에 영향을 미칠 뿐 아니라 수면은 우울감과 관련이 있어 삶의 질을 저하시키는 원인이 된다.)

요양시설 노인의 경우 살아온 생활환경의 변화와 신체적으 로 움직이는 활동량의 감소, 수면을 취하기에 적절하지 않은 상황의 노출 등은 인지활동 감소뿐 아니라 우울과 불안을 야기 시켜 의존적인 일상생활로 이어질 수 있어 본 연구에서는 요양 시설 노인에서 수면능력에 따른 인지기능과 우울감, 일상생활 수행능력을 알아보고 시설에서 수면 문제가 방치되지 않도록 조기개입과 중재를 통해 삶의 질을 향상시키고자 하였다.

\section{II. 연구방법}

\section{1. 연구기간 및 연구대상}

본 연구는 군산지역 내 요양시설에 입소한 환자를 대상으로 2017년 9월부터 3일부터 9월 30일 까지 정신의학과 전문의 로부터 경도인지장애와 치매 진단을 받은 자들을 대상으로 기 본적인 요구에 따를 수 있는 자로 청력과 시력에 문제가 없으 며 설문을 위한 기본적 의사소통에 문제가 없는 자를 연구대 상으로 선정하였다. 요양시설 2층 병동 총 입소자 56인 중 기 관 관계자의 협조 하에 본인의 이해와 동의를 얻고 본 연구에 참여를 희망하는 대상자 23 명을 선정하였다. 설문을 진행하기 위해 참여한 인원은 작업치료 전공 3 학년 학생 5 명과 기관의 작업치료사 1 인, 작업치료전공 교수 1 인, 담당간호사와 요양 보호사 2인이 본 연구의 도움을 제공하였다.

\section{2. 연구절차}

본 연구에 참여한 대상자는 임상평가척도(Clinical Dementia rating: CDR) 0.5 2단계에 해당하는 환자로 평가는 매주 금요 일 오전 10시 12시까지 수면능력 설문과, 우울감, 인지기능, 일상생활활동 수행 정도를 평가 하였다. 대상자의 집중력과 피 로감이 발생하지 않도록 사전 활동을 배제하였으며 평가 도중 대상자 피로 시 휴식 후 다시 진행하였고 대상자의 건강과 협 조 상태에 따라 자발적 참여를 확인한 후 진행하였으며 사전에 본 연구의 취지와 목적을 충분히 이해하도록 안내 하였다.

\section{3. 평가도구 \\ 1) 수면측정도구 $A$}

수면측정도구 $\mathrm{A}$ 는 수면의 질(Quality of Sleep)을 측정하기 위해서 총 15 문항으로 구성된 설문으로 모든 연령층에서 사용 이 가능하며 각 문항은 수면이 나쁠 때 나타나는 증상을 설명 하는 서술식으로 세부 문항의 내용으로는 잠드는데 오래 걸리 는지 유무에서 아침에 깬 후에 계속 졸리는지의 항목으로 응 답란은 '매우 그렇다'에 1점에서 '전혀 아니다' 4점 형식의 라 이커트 타입 도구로 구성되어 있으며 전체도구의 점수는 합산 하여 수면점수로 환산되는데 최저 15점 최고 60점이 가능하 다. 점수가 많을수록 수면의 질이 높다는 것을 의미하며 15 개 문항을 포함한 전체 도구의 Cronbach's $a$ 는 0.75 다. ${ }^{7)}$

\section{2) 우울 검사}

노인의 우울 측정은 한국판 노인 우울척도 단축형(Geriatric Depression Scale Short Form-Korean Version: GDSSF$\mathrm{K}$ )으로 총 15 문항의 '예' 나 '아니오' 양분척도로 구성되어 있으 며 총점은 15 점이며, 점수가 높을수록 우울증상이 심하다는 것을 의미하며 5점 이하는 정상, 6-9점은 중등도의 우울증상, 10 점 이 상은 우울증으로 구분한다. Cronbach's a 값은 0.87 이다. ${ }^{8)}$

\section{3) 인지기능검사}

한국판간이정신진단검사(Mini-Mental State Examination Korea; MMSE-K)는 권용철과 박종한(1989)에 의해서 한국판 간이정신진단검사로 번역된 검사로 인지기능을 알아보기 위해 임상에서 간편하게 사용하고 있다. 영역으로 '지남력', '기억등 록', '주의집중계산', '기억회상', '언어기능' '시각적 구성' '판단 능력, 이 포함되어 있으며 신뢰도는 Cronbach's a 는0.99로 30 점 만점을 기준으로 점수가 24 점 이상이면 정상, 19점 이하 인 경우는 중증장애, 20 23점이면 경도장애로 구별 된다."

\section{4) 일상생활활동 평가}

김수영과 원장원(2004)등이 노인의 일상생활 기능 평가를 위 해 우리나라 현실에 맞게 개발한 한국어판 바텔일상활동 (Barthel ADL Index)평가로 대사자의 질병 상태에 따라 변 화할 가능성과 치료효과를 입증하기 위한 반응도를 포함하며 
다른 평가 척도와의 관련성을 제시한 도구로 대변조절, 얼굴 단장하기, 식사하기, 옮겨가기, 계단 오르내리기, 소변조절, 화 장실사용, 옷 입기와 이동, 목욕의 항목을 포함한 총 10 개 항 목 20점 만점으로 Cronbach's a 값은 0.97로 점수가 높을수 록 독립적인 생활이 가능하다. ${ }^{10)}$

\section{4. 통계처리}

수집된 자료는 SPSS(v.21, IBM, USA) 프로그램을 이용하여 통계 처리하였다. 일반적인 특성은 실수와 백분율로 분석하였 다. 또한 대상자의 수면 점수 별로 인지기능, 우울감, 일상생 활 능력을 빈도, 평균과 표준편차, 비율로 분포를 알아보았다. 수면 점수 별로 인지기능, 우울감, 일상생활능력에 차이가 있 는지를 확인하고자 수면 점수 별로 나눈 4 개 그룹은 정규성을 가정할 수 있는 지를 검정하였다. Sapiro-Wilk 검정 결과 우 울감, 인지기능과 일상생활 능력은 정규성이 확인되었다 ( $\mathrm{p}>$.05). 정규성을 가정할 수 있는 우울감, 인지기능과 일상 생활 능력은 일원분산분석(One way ANOVA)으로 분석하였 고 Sheffe 사후검정을 이용하였고 유의수준을 $5 \%$ 로 하였다. 수면의 질과 우울감, 인지능력, 일상생활능력 간에 상관관계를
확인하기 위해서 Pearson상관 분석을 하였다.

\section{III. 결과}

\section{1. 연구대상자의 일반적 특성}

연구에 참여한 대상자는 총 23 명으로 여자가 $82.6 \%$ 로 대다수 를 차지하였고, 60 대에서 80 대 이상의 연령층 중에서 80 대 이상 $60.9 \%$ 를 가장 많은 분포를 보였다. 대상자의 경제 상태 는 중 $82,6 \%$, 하 $13.0 \%$, 상 $4.3 \%$ 순으로 중산층의 비율이 가장 높았다. 학력은 6 년 미만과 무학에 해당하는 대상자가 각 $43.5 \%$ 를 차지하였고, 7-9년은 $13 \%$ 이었다. 입원 기간은 1 년 미만, 2 년 미만, 4 년 이상에 해당하는 대상자는 각 $21.7 \%$ 이었고, 3 년 이하가 $26.1 \%$ 로 입원 초기인 환자부터 만성질환 으로 입원기간이 길어진 환자까지 고르게 분포한 것을 볼 수 있었다. 보행 수준을 살펴보면, 독립 보행 $60.9 \%$, 보행기를 이용한 걷기 $26.1 \%$, 지팡이를 이용한 걷기가 $8.7 \%$, 휠체어 $4.3 \%$ 로 나타났다(Table 1).

Table 1. The General Characteristics of Subjects(N=23)

\begin{tabular}{|c|c|c|c|}
\hline Characteristics & Categories & $\mathrm{n}$ & $\%$ \\
\hline \multirow{2}{*}{ Gender } & male & 4 & 17.4 \\
\hline & female & 19 & 82.6 \\
\hline \multirow{3}{*}{ Age(year) } & $80 \leq$ & 14 & 60.9 \\
\hline & $70-79$ & 8 & 34.8 \\
\hline & $60-69$ & 1 & 4.3 \\
\hline \multirow{3}{*}{ Economic Status } & high & 1 & 4.3 \\
\hline & middle & 19 & 82.6 \\
\hline & low & 3 & 13.0 \\
\hline \multirow{4}{*}{$\begin{array}{l}\text { Education } \\
\text { (year) }\end{array}$} & $10-12$ & 0 & 0 \\
\hline & 7-9 & 3 & 13.0 \\
\hline & $1-6$ & 10 & 43.5 \\
\hline & $1<$ & 10 & 43.5 \\
\hline \multirow{5}{*}{ Hospitalization Period(year) } & $>5$ & 5 & 21.7 \\
\hline & $>4$ & 2 & 8.7 \\
\hline & $>3$ & 6 & 26.1 \\
\hline & $>2$ & 5 & 21.7 \\
\hline & $1<$ & 5 & 21.7 \\
\hline \multirow{4}{*}{ Walking Status } & independent & 14 & 60.9 \\
\hline & cane & 2 & 8.7 \\
\hline & walker & 6 & 26.1 \\
\hline & wheelchair & 1 & 4.3 \\
\hline
\end{tabular}




\section{2. 수면 점수에 따른 인지기능 분포}

수면 점수 별로 인지기능의 MMSE-K 평가결과를 살펴본 결 과, 수면 점수 별 인지기능에는 유의미한 차이가 발견되지 않 았다(Table 2).

\section{3. 수면 점수에 따른 우울감 분포}

수면에 따른 노인의 우울감에 차이가 있는지를 파악하기 위해 서 GDSSF-K 점수를 수면 점수별로 살펴본 결과, 집단 간에 유의미한 차이가 발견되지 않았다(Table 3).

\section{4. 수면 점수에 따른 일상생활활동 분포}

수면 점수별로 일상생활활동 $\mathrm{BADL}$ 에 차이가 있는지를 파악 하고자 집단 간에 비교한 결과 유의미한 차이가 발견되지 않 았다(Table 4).
5. 수면의 질, 인지기능, 우울감, 일상생활활동간의 상관관계 요양시설에 입소한 노인들의 수면의 질은 인지기능, 우울감, 일상생활활동간의 상관관계가 있는지를 분석한 결과, 수면의 질은 인지기능, 우울감, 일상생활활동 간에 상관관계가 없었 다. 그러나 인지기능과 우울감은 $\mathrm{r}=-$.531로 부적 상관관계가 있는 것으로 나타났다 $(\mathrm{p}<.01)($ Table 5$)$.

\section{IV. 고 찰}

본 연구는 요양시설에 입원중인 노인을 대상으로 수면상태에 따른 인지기능과 우울감, 일상생활수행능력을 알아보고 시설 에서 수면 문제가 방치되지 않도록 조기개입과 중재를 통해 삶의 질 향상을 위해 연구 하였다. 20대에는 하루 평균 $7 \sim 8$ 시간의 수면을 취하지만 55세 이후에는 수면이 급격히 감소하

Table 2. The cognitive function according to the quality of sleep

\begin{tabular}{cccccc}
\hline Sleep score & N & M SD & $\%$ & $F$ \\
$51-60$ & 8 & $17.0 \pm 4.9$ & 34.8 & & \\
$41-50$ & 6 & $18.8 \pm 5.7$ & 26.1 & .346 & .792 \\
$31-40$ & 6 & $18.7 \pm 7.3$ & 26.1 & \\
$21-30$ & 3 & $15.3 \pm 3.8$ & 13.0 & \\
\hline
\end{tabular}

Table 3. The depression according to the quality of sleep

\begin{tabular}{cccccc}
\hline Sleep score & N & M SD & $\%$ & F & \\
$51-60$ & 8 & $4.0 \pm 1.3$ & 34.8 & 2.718 & .073 \\
$41-50$ & 6 & $2.2 \pm 1.6$ & $3.5 \pm 1.6$ & 26.1 & \\
$31-40$ & 6 & $4.7 \pm .6$ & 13.0 & \\
$21-30$ & 3 & 6.1 & \\
\hline
\end{tabular}

Table 4. The BADL according to the quality of sleep

\begin{tabular}{cccccc}
\hline Sleep score & N & M \pm SD & $\%$ & F \\
$51-60$ & 8 & $15.6 \pm 3.8$ & 34.8 & & \\
$41-50$ & 6 & $13.0 \pm 5.7$ & 26.1 & .576 \\
$31-40$ & 6 & $14.2 \pm 2.2$ & 26.1 & .638 \\
$21-30$ & 3 & $14.3 \pm 1.5$ & 13.0 & \\
\hline
\end{tabular}

Table5. The correlation among cognitive function, depression, BI, and quality of sleep

\begin{tabular}{|c|c|c|c|c|}
\hline & quality of sleep & MMSE-K & GDSSF-K & BADL \\
\hline quality of sleep & 1 & & & \\
\hline MMSE-K & -.104 & 1 & & \\
\hline GDSSF-K & .130 & $-.531^{* * *}$ & 1 & \\
\hline BADLI & .257 & .135 & .309 & 1 \\
\hline
\end{tabular}


여 64세 이상에서는 5 6시간 수면을 취하며 수면시간의 감 소와 함께 수면장애, 조기각성, 주야전도, 숙면장애 등을 경험 하는 경우가 많고, 특히 수면 중의 급속안구운동은 수면시간 이 감소함에 따라 피로 회복률이 낮아져 낮 동안의 일상적 활 동에 지장을 받는 경우가 많아지게 된다. ${ }^{11)}$

노인에서 만성질환인 비만과 관절염, 당뇨병, 뇌졸중은 수 면문제와 관련이 있으며 ${ }^{12)}$ 수면은 집중력, 기억력, 정보처리능 력을 약화시켜 생존을 위해 필요한 식사하기와 옷입기, 화장 실 사용과 이동하기뿐 아니라 복잡한 환경과 상호작용에 필요 한 능력을 저하시켜 생존을 위협하며 ${ }^{11)}$ 최근 신경학 분야 국 제 학술지인 '신경학회보'에서 60 대 이상 정상 노인이 누워서 잠들 때까지 걸리는 시간이 30 분 이상으로 길면 인지기능이 저하될 위험이 $40 \%$ 높으며 수면 시간이 8시간 이상이면 인지 기능 저하 위험이 $70 \%$ 높았다는 연구결과로 즉 긴 수면 시간 은 인지기능향상에 도움이 되지 못하여 수면의 적정시간의 중 요성을 강조 하였다. ${ }^{13)}$

낮은 수면의 질과 수면 부족은 기억의 부정적인 감정을 가 지게 될 뿐 아니라 수면의 질을 저하시켜 우울한 무드를 양산 하므로 ${ }^{14)}$ 충분한 수면과 함께 수면의 질의 중요하며, 노인에 서 잠자리에 들기까지의 걸리는 수면 패턴을 파악하고, 수면 패턴을 통해 치매 고위험군을 선별할 수 있으며 나이 들면서 수면 패턴이 바뀌게 되면 인지기능이 떨어질 위험이 높으므로 수면 패턴의 관리가 중요하다. ${ }^{13)}$

요양시설에 입원한 노인은 신체활동의 부족으로 에너지 발 산의 기회가 부족하며 반복적이고 단조로운 일과는 노인을 무 기력하게 만들며 가정과 다른 환경은 정신적, 육체적 피로감 과 스트레스를 겪게 되어 부정적인 생각으로 이어진다. 따라 서 잔존능력 유지를 위한 다양한 프로그램의 중재는 인지능력 향상뿐 아니라 우울감 개선의 유의함을 보고 하였고, ${ }^{15)}$ 보건지 소 방문건강관리대상으로 등록된 65세 이상 노인 120 명 대상 으로 설문 조사 결과 대상자 $36.2 \%$ 에서 경증우울, $39.1 \%$ 는 중증우울이 있는 것으로 나타나 연구대상자의 $75.3 \%$ 가 우울 을 경험하고 있었으며 인지기능은 우울, 연령, 허약수준과 통 계적으로 유의한 부적 상관관계가 있는 것으로 보고 하여 지 역사회노인의 우울을 완화하고 인지기능저하를 예방할 수 있 는 효과적인 프로그램 개발의 필요성을 제시하였다. ${ }^{16-17)}$

본 연구 결과 수면의 질에서 수면 점수 별로 인지기능, 우 울감, 일상생활활동은 유의미한 차이가 없어 수면의 질과 인 지기능, 우울감, 일상생활능력 간에 상관관계는 나타나지 않았 으나 우울감과 인지기능 간에는 유의미한 상관관계가 있는 것 으로 나타났다 $(\mathrm{p}<.01)$. 세 항목간의 상관관계가 없었던 연구 자의 견해는 대상자에서 수면 점수에 따른 인지기능, 우울, 일 상생활 수행능력에 차이가 없었던 점, 70 세 이상 80세 연령이 22 명 $94 \%$ 로 수면장애 요인이 고령인 연령이나 만성통증이나
보행 관련 등의 변수 작용이 있을것으로 사료되며, 노년기의 인지기능은 우울감과 높은 상관관계를 보이므로 요양시설 내 노인의 인지기능을 활성화할 수 있는 프로그램의 개발 및 적 용은 향후 노인인구의 우울감을 감소시키는 데 효과적일 수 있을 것으로 예측하며 전체 대상자 중에서 $60.9 \%$ 만 독립 보 행이 가능하였고 대략 $40 \%$ 는 보조도구를 이용한 보행을 하고 있는 대상자로 향후 연구에서는 보조도구의 사용 유무에 따른 대상자의 수면의 질을 파악해볼 필요성이 있다고 본다.

\section{References}

1. KISOUKUBOTA. Hand and Brain. TOKO: Japan: badabooks. 2014; 2-120

2. Yang CK, Yoo SY, Joo YH, Hahn HM. Sleep habits and sleep disorders among the elderly between 65-84 years who are living in a part of Pusan. Sleep Med Psychophysiol. 1997;4:66-76.

3. Nath RD, Bedbrook CN, Abrams MJ, Basinger T, Bois JS, Prober DA, Sternberg PW, Gradinaru V, Goentoro L. The Jellyfish Cassiopea Exhibits a Sleep-like State. Curr Biol. 2017; 9:27(19):2984-2990

4. Kim L, Kang SG. Sleep Physiology and Common Sleep Disorders in the Elderly. Sleep Med Psychophysiol. 2007;14(1):5-12.

5. Yoon IN. Introduction to Sleep Disorders. Hanyang Medical Reviews. 2013.33;197-202.

6. Park SJ. The Subjective memory complaint, cognitive function and psychological aspects according to Sleep quality in elders. Department of Psychology. The Graduate School, Catholic University of Daegu. 2015.

7. Oh JJ, Song MS, Kim SM. Development and Validation of Korean Sleep Scale A. Journal of Korean Academy of Nursing. 1993;28(3):563-572.

8. Kee BS. A Preliminary Study for the Standardization of Geriatric Depression Scale Short Form-Korea Version. J Korean Neuropsychiatr Assoc. 2013. 35; 2:298-305.

9. Gwon YC \& Bak JH. Development of the Test for the Elderly $=$ Korean Version of Mini-Mental State Examination (MMSE-K), Journal of the Korean. Neuropsychiatric Association. 1989;28:1.

10. Kim SY, Won CW, Rho YG. The Validity and Reliability of Korean Version of Bathel ADL Index. J Korean Acad Fam Med. 2004;25(7):534-541.

11. Yang YA, Lee HS, et al. Elderly occupational therapy. First edition, Seoul, GYECHUK MUNWHASA. 2016;35-50. 
12. Foley D1, Ancoli-Israel S, Britz P, Walsh J. Sleep disturbances and chronic disease in older adults: results of the 2003 National Sleep Foundation Sleep in America Survey. J Psychosom Res. 2004;56(5):497-502.

13. Suh SW, Han JW, Lee JR, et al. Sleep and cognitive decline: A prospective nondemented elderly cohort study. Ann Neurol. 2018;83(3):472-482.

14. Empesta D, De GL, Natale V, Ferrara M. Emotional memory processing is influenced by sleep quality. Sleep Med. 2015;16(7):862-70.

15. Chong BH, Park JJ, Chung, SM. Effect of Craft Program of Occupational Therapy on Cognitive Function,
Depression, Activity of daily living and Hand function in patients with Dementia living in a community. NEUROTHERAPY. 2016;20(2): 47-52.

16. Seo SO, So AY. J Korean Acad Community Health Nurs Depression and Cognitive Function of the Community-dwelling Elderly. 2016;27(1):1-8.

17. Kim SY, Kim YS, N YH, K H. Task-Oriented Approach Program on Self-Efficacy Scale and Activities of Daily Living, Geriatric Quality Of Life in Dementia Patients. Society of Occupational Therapy for the Aged and Dementia. 2018;12(1):21-33. 